\title{
TRATAMENTOS HIDROTÉRMICO E COM RADIAÇÃO UV-C NO CONTROLE PÓS-COLHEITA DA PODRIDÃO OLHO-DE-BOI EM UMA LINHA COMERCIAL DE SELEÇÃO DE MAÇÃ̃ ${ }^{1}$
}

\author{
VINÍCIUS ADÃO BARTNICKI ${ }^{2}$, ROSA MARIA VALDEBENITO-SANHUEZA ${ }^{3}$ \\ CASSANDRO VIDAL TALAMINI DO AMARANTE ${ }^{4}$, CRISTIANO ANDRÉ STEFFENS
}

RESUMO - Avaliaram-se os efeitos da aspersão hidrotérmica e da radiação UV-C no controle pós-colheita da podridão olho-de-boi (POB) em maçãs 'Fuji', após um e oito meses de armazenamento, e 'Gala', após cinco meses de armazenamento, ambas sob condição de atmosfera controlada (AC). Esses frutos foram inoculados ou mantidos com infecção natural de Cryptosporiopsis perennans. As maçãs 'Fuji' foram submetidas aos seguintes tratamentos, aplicados em uma linha comercial de seleção: sem tratamento (testemunha); aspersão hidrotérmica (água a $50^{\circ} \mathrm{C}$ por 12 segundos); radiação UV-C $\left(0,0069 \mathrm{~kJ} \mathrm{~m}^{-2}\right)$; e aspersão hidrotérmica + radiação UV-C. As maçãs 'Gala' também foram submetidas a estes tratamentos utilizados em 'Fuji', exceto ao tratamento com aspersão hidrotérmica + radiação UV-C. Após os tratamentos, as maçãs foram incubadas a $22^{\circ} \mathrm{C}$ por 15 dias e avaliadas quanto à incidência da doença. Nas maçãs 'Fuji', os tratamentos de aspersão hidrotérmica e/ou radiação UV-C reduziram a incidência da POB nos frutos inoculados e com infecção natural, proporcionando controle superior a $56 \%$ e $54 \%$, em relação à testemunha, respectivamente. Em maçãs 'Gala' inoculadas, os tratamentos com aspersão hidrotérmica e radiação UV-C também reduziram o número de unidades formadoras de colônias (UFC) nos frutos, com controle superior a 70\%, e a incidência da POB, com controle superior a $69 \%$ em relação à testemunha. Em maçãs 'Gala', com infecção natural, estes tratamentos apresentaram controle da POB superior a $85 \%$ em relação à testemunha. Os resultados obtidos mostram que os tratamentos com aspersão hidrotérmica e/ou radiação UV-C reduzem a incidência da POB em maçãs 'Fuji' e 'Gala', em linha comercial de seleção. Todavia, o uso da radiação UV-C, em ambas as cultivares, foi o tratamento que apresentou maior benefício e retorno econômico.

Termos para indexação: Malus domestica, Cryptosporiopsis perennans, desinfestação, aspersão de água aquecida, irradiação.

\section{HYDROTHERMALAND UV-C RADIATION TREATMENTS FOR POSTHARVEST CONTROL OF BULL'S-EYE ROT OF APPLES IN A COMMERCIAL PACKING LINE}

ABSTRACT - This research was carried out to evaluate the effects of hydrothermal and UV-C radiation treatments for postharvest control of bull's-eye rot (BER) on 'Fuji' apples, after one and eight months storage under controlled atmosphere (CA) and 'Gala' apples, after five months storage under CA. These fruits were inoculated or naturally infected with Cryptosporiopsis perennans (causal agent of BER). 'Fuji' apples were submitted to the following treatments implemented in a commercial packing line: 1) Control; 2) Hydrothermal treatment (water at $50^{\circ} \mathrm{C}$, sprayed for 12 seconds); 3) UV-C radiation $\left(0.0069 \mathrm{~kJ} \mathrm{~m}^{-2}\right)$; and 4) Hydrothermal treatment + UV-C radiation. 'Gala' apples were submitted to the same treatments described for 'Fuji', except the hydrothermal treatment water + UV-C radiation. After the treatment, the apples were incubated at $22^{\circ} \mathrm{C}$ for 15 days and assessed for incidence. On 'Fuji' apples, the hydrothermal treatment and/or UV-C radiation was efficient, providing more than $56 \%$ and $54 \%$ reduction of BER compared to the control, in fruit inoculated and with natural infection of $C$. perennans, respectively. On 'Gala' apples inoculated with C. perennans, the ermal treatment and UV-C radiation were equally effective to reduce the number of colony formation units (CFU) recovered from treated fruits (more than $70 \%$ reduction in comparison to the control) and BER incidence (more than $69 \%$ reduction in comparison to the control). On 'Gala' apples with natural infection, these treatments provided more than $85 \%$ reduction of BER compared to the control. The results show that hydrothermal treatment (water at $50^{\circ} \mathrm{C}$, sprayed for 12 seconds) and UV-C radiation $\left(0.0069 \mathrm{~kJ} \mathrm{~m}^{-2}\right)$ are equally effective to control BER on 'Gala' e 'Fuji' apples when implemented in a commercial packing line. However, UV-C radiation was the most effective treatment and had the best economical return in both cultivars.

Index terms: Malus domestica, Cryptosporiopsis perennans, disinfestation, heated water spraying, irradiation.

\footnotetext{
1( Trabalho 207-10). Recebido em: 07-10-2010. Aceito para publicação em: 06-05-2011.

${ }^{2}$ Aluno de Curso de Doutorado em Produção Vegetal, Centro de Ciências Agroveterinárias/UDESC. Lages- SC. E-mail: vinibart@hotmail.com ${ }^{3}$ Dra., Bolsista de Produtividade em Pesquisa do CNPq. Pesq. da Proterra Engenharia Agronômica. Vacaria-RS.E-mail: rosamaria@m2net.com.br ${ }^{4} \mathrm{Ph} . D$.,Prof. do Dept ${ }^{\circ}$. de Agronomia, Centro de Ciências Agroveterinárias/UDESC. Lages-SC, Brasil. Bolsista de Produtividade em Pesquisa do CNPq. E-mail: amarante@cav.udesc.br

${ }^{5}$ Dr., Professor do Dept ${ }^{\circ}$. de Agronomia, Centro de Ciências Agroveterinárias/UDESC. Lages-SC, Brasil. E-mail: steffens@cav.udesc.br
} 


\section{INTRODUÇÃO}

No Sul do Brasil, a podridão olho-de-boi (POB), causada pelo fungo Cryptosporiopsis perennans, vem causando perdas crescentes de maçãs durante a pós-colheita, principalmente em maçãs 'Fuji'. Infecções latentes causadas por C. perennans podem causar perdas de até $34,4 \%$ dos frutos, não se dispondo de práticas adequadas para a sua redução (VALDEBENITO-SANHUEZA et al., 2010). Os sintomas de $C$. perennans nos frutos caracterizam-se por uma podridão marrom-clara, de forma circular, às vezes com margens marrom-escuras ou avermelhadas, deprimida, de textura firme e desenvolvimento lento. Os tecidos internos são de cor amarelada e firme. As podridões iniciadas em lesões causadas por ferimentos no campo são mais amareladas que as que se desenvolvem em pós-colheita, apresentam a polpa desidratada e em formato de cavernas (VALDEBENITO-SANHUEZA, 2002). Este patógeno penetra através de lenticelas e aberturas naturais, como a calicinal e a peduncular (EDNEY; BURCHILL, 1967). Quando os conídios penetram pelas lenticelas, podem tornar-se inacessíveis a fungicidas, pois aderem-se a estas estruturas e a microfissuras da cutícula (BARTNICKI et al., 2010).

A imersão das maçãs em água clorada é o principal método utilizado para reduzir a quantidade de inóculo antes e/ou após o armazenamento e antes da embalagem. Porém, além de causar corrosão do maquinário processador, o tratamento com cloro pode ser ineficaz em frutos com grande quantidade de matéria orgânica e com alta contaminação por microrganismos (SADIQ; RODRIGUEZ, 2004). $\mathrm{O}$ resultado disso pode ser observado através das perdas após a embalagem nos mercados interno ou externo, tendo como consequência a devolução de lotes, contabilizando grandes prejuízos para as empacotadoras. Assim, outros métodos de controle que reduzam a quantidade de inóculo nas maçãs trariam benefícios para toda a cadeia produtiva de maçãs. Entre os métodos alternativos ao uso de fungicidas para o controle de doenças pós-colheita, a aspersão hidrotérmica e a radiação UV-C oferecem possibilidades interessantes.

O tratamento térmico tem sido utilizado como agente esterilizante há muitos anos, mas, apenas a partir do fim da década de 60 , tem recebido atenção para controlar podridões pós-colheita de frutos (EDNEY;BURCHILL, 1967). A sua utilização em pré-armazenamento, com temperaturas e períodos diversos, é eficaz no controle de pragas e doenças, e para retardar o amadurecimento de frutos (LURIE, 2006; JIN et al., 2009). Em maçãs 'Golden Delicious' inoculadas com Penicillium expansum, o tratamento com ar aquecido a $38^{\circ} \mathrm{C}$ por quatro dias reduziu a ocorrência de podridões em frutos armazenados a $0^{\circ} \mathrm{C}$ por seis meses (SAMS et al., 1993). Em maçãs 'Cox's Orange Pippin', o tratamento dos frutos por imersão hidrotérmica e com temperaturas variando de $42^{\circ} \mathrm{C}$ a $48^{\circ} \mathrm{C}$, por 5 a 20 minutos, reduziu a infecção de Gloeosporium spp., agente causal da POB na Europa, em frutos armazenados a $5^{\circ} \mathrm{C}$ por 12 semanas (EDNEY; BURCHILL, 1967). Para o controle desta podridão em maçãs oriundas de produção orgânica, tem-se utilizado o tratamento hidrotérmico a $53^{\circ} \mathrm{C}$ por três minutos (MAXIN et al., 2005).

$\mathrm{O}$ tratamento com radiação $\mathrm{UV}-\mathrm{C}(\lambda=254 \mathrm{~nm})$, na dose adequada, pode induzir resistência a patógenos no tecido vegetal e, assim, reduzir a incidência de doenças pós-colheita (STEVENS et al., 1996; 2005). Li et al. (2008), trabalhando com bagas de uva 'Carigane', irradiadas com doses de UV-C variando de 1,2 a $3,6 \mathrm{~kJ} \mathrm{~m}^{-2}$ e incubadas a $20^{\circ} \mathrm{C}$ por 24 horas, observaram incremento no conteúdo de transresveratrol de sua epiderme. Além da indução de resistência, alguns resultados sugerem que o controle de podridões pode ser devido ao efeito germicida da radiação UV-C sobre a população epífita de microrganismos (CHUN et al., 2010; SOMMERS et al., 2010), o que contribuiria para o controle de propágulos de alguns patógenos presentes na superfície dos frutos antes da embalagem.

Os frutos imaturos apresentam maior resistência a patógenos, sendo que as mudanças fisiológicas verificadas na pós-colheita aumentam a suscetibilidade da parede celular às enzimas pectinolíticas produzidas pelos patógenos, favorecendo a infecção (BORSANI et al., 2009). A incidência da infecção ocasionada por $C$. perennans em maçãs é maior quando o fruto está próximo do ponto de colheita, mas as maiores perdas ocorrem durante e após o armazenamento refrigerado (VALDEBENITOSANHUEZA, 2002).

Bartnicki et al. (2010) mostraram a suscetibilidade do agente causal da podridão olho-de-boi, no Brasil, ao tratamento hidrotérmico e à radiação UV-C, sob condições controladas. Contudo, não há informações disponíveis sobre o uso prático da aspersão hidrotérmica e da radiação UV-C no controle pós-colheita desta podridão em maçãs. $\mathrm{O}$ objetivo deste estudo foi avaliar a eficiência técnica e a viabilidade econômica da aspersão hidrotérmica e da radiação UV-C no controle da $\mathrm{POB}$ em maçãs 'Fuji' e 'Gala', inoculadas artificialmente e com infecção natural, após armazenamento em condição de atmosfera controlada. 


\section{MATERIAL E MÉTODOS}

Os experimentos foram conduzidos no Centro de Pesquisa Proterra (CPPro) e na empacotadora da Empresa Rasip Agro Pastoril S.A., ambos localizados em Vacaria-RS, no ano de 2009. Os frutos utilizados neste trabalho foram colhidos em pomares comercias com histórico de incidência da POB, localizados neste mesmo município.

Maçãs 'Fuji' com peso variando entre $127 \mathrm{~g}$ até $141 \mathrm{~g}$ (correspondente ao calibre 135, segundo normas de classificação de maçãs do Brasil, 2002), armazenadas durante um e oito meses em condição de atmosfera controlada (AC; $1,5 \mathrm{kPa}$ de $\mathrm{O}_{2}+0,5$ $\mathrm{kPa}$ de $\mathrm{CO}_{2}$ ) a $0,5 \pm 0,5^{\circ} \mathrm{Ce} 95 \pm 2 \% \mathrm{UR}$, com infecção natural ou após inoculação de C. perennans, foram submetidas aos seguintes tratamentos, em uma linha comercial de seleção: 1) sem tratamento (testemunha); 2) aspersão hidrotérmica (com água aquecida a $50^{\circ} \mathrm{C}$, por 12 segundos; 3 ) radiação UV-C na dose de $0,0069 \mathrm{~kJ} \mathrm{~m}^{-2} ; \mathrm{e} 4$ ) aspersão hidrotérmica (com água aquecida a $50^{\circ} \mathrm{C}$, por 12 segundos) + radiação UV-C $\left(0,0069 \mathrm{~kJ} \mathrm{~m}^{-2}\right)$. Os frutos armazenados por um e oito meses em AC apresentavam, respectivamente, teores de sólidos solúveis (SS) de 15,0 e 13,5 ${ }^{\circ}$ Brix, e firmeza de polpa de 64,3 e 71,5 Newtons (N). Em frutos inoculados, foram utilizadas quatro a sete repetições de três a cinco frutos. Em frutos com infecção natural, foram utilizadas quatro a seis repetições de 30 frutos.

Maçãs 'Gala' com peso variando entre $87 \mathrm{~g}$ até 95g (correspondente ao calibre 198, segundo normas de classificação de maçãs do Brasil, 2002), armazenadas por cinco meses em condição de $\mathrm{AC}(2,0 \mathrm{kPa}$ de $\mathrm{O}_{2}+1,5 \mathrm{kPa}$ de $\mathrm{CO}_{2}$ ) a $0,5 \pm 0,5^{\circ} \mathrm{C}$ e $95 \pm 2 \% \mathrm{UR}$, inoculadas ou com infecção natural de C.perennans, foram submetidas aos mesmos tratamentos utilizados em 'Fuji', exceto o tratamento combinado de aspersão hidrotérmica + radiação UV-C. Os frutos apresentavam SS de $11,7^{\circ}$ Brix e firmeza de polpa de 73,5 N. Em frutos inoculados, foram utilizadas oito repetições de 10 frutos. Em frutos com infecção natural, foram utilizadas quatro repetições de 100 frutos.

Os frutos foram inoculados antes da aplicação dos tratamentos físicos, sendo que foi utilizado o isolado $C p 5$ de C.perennans (CNPUV/Va-5). As maçãs foram submetidas a uma desinfestação prévia com álcool. Antes da inoculação, para condicionamento, as maçãs foram armazenadas na temperatura de $20^{\circ} \mathrm{C}$, por $24 \mathrm{~h}$, em câmara úmida. Após esse período, as maçãs foram pulverizadas com uma suspensão de $1 \times 10^{7}$ conídios $\mathrm{mL}^{-1}$ de C.perennans. Maçãs 'Fuji' e 'Gala' inoculadas foram incubadas a $22^{\circ} \mathrm{C}$ durante sete dias e $24 \mathrm{~h}$, respectivamente, antes da aplicação dos tratamentos físicos. Em 'Gala', o período de incubação foi de apenas $24 \mathrm{~h}$, tendo em vista a avaliação, nesta cultivar, da desinfestação dos frutos submetidos aos tratamentos com aspersão hidrotérmica e radiação UV-C. Para isto, logo após os tratamentos, quatro repetições de três frutos foram submetidas à lavagem por sonificação durante 30 segundos, sendo usados $200 \mathrm{~mL}$ de água destilada e esterilizada para cada repetição. Alíquotas de $0,1 \mathrm{~mL}$ da lavagem dos frutos foram distribuídas em placas de Petri com meio seletivo para C. perennans (SPOLTI et al., 2010) e incubadas por sete dias a $22^{\circ} \mathrm{C}$, sob luz fluorescente contínua (tipo luz do dia). Nas placas, avaliou-se a sobrevivência de conídios recuperados da superfície dos frutos, estimada pelo número de unidades formadoras de colônias (UFC). Através das UFC nas placas, foi estimado o número de UFC por fruto. Foram usadas três placas para contagem de colônias de cada repetição da lavagem.

A aplicação dos tratamentos físicos nos frutos foi realizada acoplando os equipamentos de aspersão hidrotérmica e de radiação UV-C em uma linha comercial de seleção (Marca Prodol), a qual possuía rolos de alumínio, girando a $12 \mathrm{rpm}$.

Para a aspersão hidrotérmica dos frutos, foi utilizado um conjunto de aquecimento de água e outro de aspersão. O primeiro compreendeu um recipiente com resistências elétricas e termostato para controlar a temperatura. O segundo foi composto de nove barras (contendo cinco bicos de aspersão do tipo cone vazio, distanciados entre si em $25 \mathrm{~cm}$ ), distribuídas a cada $30 \mathrm{~cm}$ na linha de classificação, uma bomba e um motor. O sistema de aspersão foi ajustado para que a distância entre a saída do bico e o fruto fosse de $10 \mathrm{~cm}$, sendo a temperatura do tratamento aferida neste percurso.

O equipamento de radiação UV-C foi composto de nove lâmpadas UV-C (Marca Ecolume), com potência de 40 watts cada, distanciadas entre si em $20 \mathrm{~cm}$, emitindo radiação com comprimento de onda de 254 nanômetros. As lâmpadas foram instaladas em uma caixa de madeira, dimensionada para que a radiação não fosse emitida para fora da linha de seleção, uma vez que poderia comprometer a saúde dos trabalhadores. A distância entre a fonte de radiação UV-C e o fruto foi de $10 \mathrm{~cm}$. A radiação UV-C foi aferida conforme metodologia descrita por Bartnicki et al. (2010).

Após a aplicação dos tratamentos, maçãs 'Fuji' e 'Gala' foram incubadas a $22^{\circ} \mathrm{C}$ e, após 15 dias, avaliadas quanto ao número de maçãs com sintomas (incidência) da POB, conforme descrito por Valdebenito-Sanhueza (2002).

Utilizou-se o delineamento inteiramente casualizado em todos os experimentos. Os dados de 
incidência de POB (em 'Fuji' e 'Gala') e de UFC (em 'Gala') foram transformados para arco-seno $[(\mathrm{x}+1) / 100]^{1 / 2} \mathrm{e}(\mathrm{x}+1)^{1 / 2}$, respectivamente, antes de serem submetidos à análise de variância, utilizando o programa SAS (SAS INSTITUTE, 2002). As médias de tratamentos foram comparadas pelo teste de Tukey $(\mathrm{p}<0,05)$.

Os resultados obtidos no controle de POB em maçãs com infecção natural foram utilizados para a análise de retorno financeiro do uso dos tratamentos físicos, levando em consideração o custo de implementação (equipamentos e a montagem), a aplicação (energia consumida) e as perdas ocasionadas pela POB na testemunha. Com isso, foi obtido o benefício das aplicações (receita - despesa) e a relação entre $\mathrm{R} \$$ investido/ $\mathrm{R}$ \% retorno pelo controle da doença (VALDEBENITO-SANHUEZA et al., 2010).

A aspersão hidrotérmica teve como custo de implementação e de consumo diário de energia $\mathrm{R} \$ 7.000,00$ e $\mathrm{R} \$ 622,80$, respectivamente. Para o sistema de radiação, esses valores foram de R\$ $6.700,00$ e R\$18,00, respectivamente. Para os cálculos de benefício e retorno econômico, levou-se em consideração que os equipamentos de aspersão hidrotérmica e radiação UV-C possuem uma vida média de 90 dias, cada equipamento é capaz de tra$\operatorname{tar} 40.500 \mathrm{~kg}$ de maçãs em cada linha $/$ dia $^{-1}$, o preço da energia por kW é de R \$ 6,24 (RGE, 2010), e os preços por kg de maçãs 'Fuji' e 'Gala' são de R\$ 1,60 e $\mathrm{R} \$ 1,34$, respectivamente, conforme valores médios obtidos no site de cotações agrícolas Agrolink (2009) para o período em que os frutos foram tratados. O cálculo de viabilidade econômica para a cultivar Fuji foi realizado com a perda média dos dois períodos avaliados (um e oito meses em AC).

\section{RESULTADOS E DISCUSSÃO}

A incidência natural da POB nas maçãs 'Fuji' sem tratamento físico foi de $15,5 \%$ e $11,7 \%$ nas amostras com um e oito meses de AC, respectivamente, e foi de $2,1 \%$ em maçãs 'Gala' com cinco meses de AC, comprovando a importância desta doença no Sul do Brasil. A baixa incidência da POB em maçãs 'Gala' é justificada por sua colheita precoce, quando comparada a outras cultivares, como 'Fuji' e 'Pink Lady'. Assim, a menor permanência dos frutos no campo garante um menor período de exposição à pressão de inóculo e, consequentemente, uma baixa incidência da POB (VALDEBENITOSANHUEZA, 2002).

Em maçãs 'Fuji' inoculadas ou com infecção natural de C. perennans, os tratamentos de aspersão hidrotérmica e de radiação UV-C, aplicados isoladamente ou em combinação, reduziram a incidência de POB em relação à testemunha, independentemente do período de armazenamento em AC (Tabela 1).

Maçãs 'Fuji' submetidas à inoculação, após um e oito meses de armazenados em AC, apresentaram $66,7 \%$ e $51,4 \%$ de incidência de POB, respectivamente, no tratamento-testemunha. Quando submetidos aos tratamentos com aspersão hidrotérmica ou radiação UV-C, a incidência de POB foi reduzida para $12 \%$ e $23 \%$ com um e oito meses de armazenamento em condição de $\mathrm{AC}$, respectivamente, o que representa um controle da doença, em relação à testemunha, de $81 \%$ e $56 \%$. Já o tratamento combinado de aspersão hidrotérmica + radiação UV-C, resultou em $0 \%$ e $17 \%$ de incidência de $\mathrm{POB}$, em frutos armazenados durante um e oito meses em AC, respectivamente. Em frutos inoculados após um mês de armazenamento em $\mathrm{AC}$, o tratamento com aspersão hidrotérmica + radiação UV-C foi mais eficiente na redução da incidência da POB do que os tratamentos físicos testados isoladamente.

Em maçãs 'Fuji' com infecção natural, armazenadas durante um e oito meses em AC, os tratamentos físicos utilizados apresentaram resultados similares àqueles obtidos em frutos inoculados (Tabela 1). Todavia, a incidência de POB em frutos com infecção natural foi menor do que em frutos inoculados. Todos os tratamentos físicos testados (aspersão hidrotérmica, radiação UV-C e aspersão hidrotérmica + radiação UV-C) reduziram igualmente a incidência da POB (53\% a 79\% de redução em relação à testemunha, dependendo do período de armazenamento em AC), apresentando incidência de 2,5\% a 7,2\% (Tabela 1).

Em maçãs 'Gala' armazenadas durante cinco meses em AC e inoculadas com $C$. perennans, o número de UFC recuperadas nos frutos, bem como a incidência da POB nos mesmos, após a aplicação dos tratamentos de aspersão hidrotérmica e de radiação UV-C, foram significativamente menores em relação à testemunha (Tabela 2). Ainda, os dois métodos físicos testados apresentaram mais de $87 \%$ e $69 \%$ de controle, em relação à testemunha, no número de UFC e na incidência de POB nos frutos, respectivamente.

Em maçãs 'Gala' com infecção natural de $C$. perennans, os tratamentos de aspersão hidrotérmica e de radiação UV-C reduziram igualmente a incidência da $\mathrm{POB}$, sendo superior a $85 \%$ em relação à testemunha (Tabela 3). A incidência de POB foi de $2,1 \%$ na testemunha, e de $0,3 \%$ e $0,2 \%$ após os tratamentos de aspersão hidrotérmica e radiação UV-C, respectivamente.

A redução da incidência da $\mathrm{POB}$ em maçãs tratadas com aspersão hidrotérmica pode ser atribuída 
ao efeito letal da temperatura sobre os esporos do patógeno (BARTNICKI et al., 2010) e à remoção dos mesmos através da aspersão (LURIE, 2006). Adicionalmente, o tratamento térmico pode induzir mecanismos de defesa nas camadas mais externas do epicarpo, o que inibe a infecção quiescente de patógenos nos frutos (FALLIK, 2004). A indução de resistência poderia ser confirmada se os frutos tivessem sido inoculados após os tratamentos físicos. Porém, avaliou-se apenas a infecção natural de $C$. perennans, que corresponde ao patógeno presente no fruto antes da colheita, mas que, devido aos mecanismos de defesa do vegetal, não há manifestação de sintomas da doença (VALDEBENITO-SANHUEZA, 2002). Assim, em pós-colheita, quando diminuem os mecanismos de defesa dos frutos, associados às temperaturas próximas de $20^{\circ} \mathrm{C}$, o patógeno desenvolve a podridão (BORSANI et al., 2009).

Perdas durante o armazenamento, causadas por Botrytis cinerea, P. expansum ou Gloeosporium spp., foram reduzidas em maçãs inoculadas e tratadas com temperaturas mais baixas que a usada neste trabalho, porém com maior período de exposição. A exposição de maçãs à temperatura de $38^{\circ} \mathrm{C}$, durante quatro dias, foi eficiente no controle de P. expansum (FALLIK, 2004). Os tratamentos por imersão hidrotérmica, nas temperaturas de $42^{\circ} \mathrm{C}$ a $48^{\circ} \mathrm{C}$, por 5 a 20 minutos (EDNEY; BURCHILL, 1967), ou a imersão a $53^{\circ} \mathrm{C}$ por três minutos, em maçãs com infecção natural (MAXIN et al., 2005), controlaram a POB. O período de aspersão de 12 segundos a $50^{\circ} \mathrm{C}$, testado neste trabalho, mostra maior viabilidade do ponto de vista prático, em relação aos demais métodos de tratamento térmico citados na literatura, uma vez que, além de exigir menor demanda de energia para o aquecimento e manutenção da temperatura desejada da água, não interfere no rendimento da classificação e da embalagem da empacotadora.

A redução de UFC de $C$. perennans da superfície de maçãs 'Gala' inoculadas e tratadas com radiação UV-C pode ser atribuída ao efeito germicida da radiação (BARTNICKI et al., 2010). Conforme Demirci e Panico (2008), este efeito ocorre pela destruição de estruturas do patógeno, inibição da germinação ou retardo no desenvolvimento do fungo, pela desnaturação proteica e desorganização da membrana plasmática. Em condições de manejo comercial, Valdebenito-Sanhueza e Maia (2001) atribuíram o controle de $P$. expansum, em maçãs 'Fuji' com alta contaminação, ao efeito germicida da radiação UVC, uma vez que ocorreu redução de 90 a $100 \%$ dos propágulos presentes na superfície dos frutos.

Conforme $\mathrm{Lu}$ et al. (1993), a radiação UV-C não penetra no tecido dos frutos $\mathrm{e}$, portanto, não atinge infecções já estabelecidas. Alguns pesquisadores atribuem a redução de doenças à indução de resistência ao patógeno que a radiação UV-C causa no hospedeiro (STEVENS et al., 1996; 2005). Stevens et al. (2005) usaram a dose de radiação UV-C de $7,5 \mathrm{~kJ} \mathrm{~m}^{-2}$, para a indução de resistência e redução de podridões em maçãs 'Golden Delicious' inoculadas com Colletotrichum gloeosporioides. A radiação UV-C na dose de $2,4 \mathrm{~kJ} \mathrm{~m}^{-2}$ induziu a síntese da fitoalexina transresveratrol em maçãs 'Fuji', porém não foi eficiente no controle da podridão causada por $P$. expansum, durante sete meses de armazenamento em AC (SAUTTER et al., 2008).

Segundo Stevens et al. (1996), em maçãs 'Golden Delicious', a melhor dose de radiação UV-C para redução de podridões pós-colheita causadas por Monilinia spp., Alternaria spp. e C. gloeosporioides foi de $7,5 \mathrm{~kJ} \mathrm{~m}^{-2}$, sendo que as doses testadas variaram de 0 a $40 \mathrm{~kJ} \mathrm{~m}^{-2}$. Os mesmos autores observaram que o patógeno de mais difícil controle foi Alternaria spp. Para a redução das infecções naturais causadas por Penicillium digitatum, Alternaria citri e Geotrichum candidum em tangerinas, as doses mais efetivas de radiação UV-C variaram de 0,84 a $3,6 \mathrm{~kJ} \mathrm{~m}^{-2}$, sendo que a dose de $1,3 \mathrm{~kJ} \mathrm{~m}^{-2}$ foi eficiente no controle de $P$. digitatum (STEVENS et al., 1996). O controle in vitro de $C$. perennans foi obtido com a dose de radiação UV-C de $0,750 \mathrm{~kJ} \mathrm{~m}^{-2} \mathrm{e}$, in vivo, em maçãs 'Fuji', em uma linha experimental de seleção, com a dose de $0,375 \mathrm{~kJ} \mathrm{~m}^{-2}$ (BARTNICKI et al., 2010). Neste trabalho, a radiação UV-C $\left(0,0069 \mathrm{~kJ} \mathrm{~m}^{-2}\right)$, em dose não testada anteriormente e bem menor do que as citadas por outros autores, reduziu o número de conídios de $C$. perennans presentes na superfície de maçãs 'Gala' e a incidência da POB em maçãs 'Gala' e 'Fuji' (Tabelas 1; 2 e 3).

Os tratamentos com aspersão hidrotérmica e/ ou radiação UV-C trouxeram vantagem econômica para o controle da POB em maçãs 'Fuji' e 'Gala' (Tabela 4). O uso da radiação UV-C, em ambas as cultivares, foi o tratamento que apresentou maior benefício e retorno econômico. $\mathrm{O}$ benefício com os tratamentos de aspersão hidrotérmica e de radiação UV-C foi, respectivamente, de R $\$ 4.700,00 /$ dia $^{-1}$ e $\mathrm{R} \$ 5.845,00 / \mathrm{dia}^{-1}$ em maçãs 'Fuji', e de R $\$ 337,00 /$ dia $^{-1}$ e R $\$ 954,00 /$ dia $^{-1}$ em maçãs 'Gala'. O retorno ( $\mathrm{R} \$$ de retorno por $\mathrm{R} \$$ investido) com aspersão hidrotérmica e radiação UV-C, foi, respectivamente, de $\mathrm{R} \$ 7,70$ e R\$ 64,00 em maçãs 'Fuji', e de R\$ 1,48 e R\$ 11,32 em maçãs 'Gala'. A associação dos tratamentos, aspersão hidrotérmica + radiação UV-C, não trouxe maior benefício e retorno quando comparado ao tratamento com radiação UV-C. Quando se comparam estes parâmetros econômicos entre 
cultivares, observa-se maior viabilidade econômica do tratamento na 'Fuji' do que na 'Gala', justificada pela baixa incidência da POB em 'Gala'.

Os tratamentos com aspersão hidrotérmica e radiação UV-C estudados neste trabalho apresentam como benefícios o curto período de exposição necessário para o controle do patógeno, a existência de equipamentos de segurança acessíveis e o fato de não deixarem resíduos na superfície dos frutos. Contudo, para assegurar o controle de POB em maçãs, a radiação UV-C pode ser mais vantajosa às embaladoras do que o uso de aspersão hidrotérmica, principalmente pelo menor investimento, maior eficiência econômica e maior facilidade de implementação em escala comercial.

TABELA 1 - Incidência (\%) e controle (\% em relação à testemunha) da podridão olho-de-boi em maçãs 'Fuji’, após um e oito meses de armazenamento sob $\mathrm{AC}\left(1,5 \mathrm{kPa}\right.$ de $\mathrm{O}_{2}+0,5 \mathrm{kPa}$ de $\left.\mathrm{CO}_{2}\right)$ a $0,5^{\circ} \mathrm{C} \mathrm{e}$ 95\% UR, inoculadas ou com infecção natural de Crysptosporiopsis perennans, submetidas a tratamentos com aspersão hidrotérmica e radiação UV-C, em uma linha comercial de seleção.

\begin{tabular}{|c|c|c|c|c|}
\hline \multirow{2}{*}{ Tratamento } & \multicolumn{2}{|c|}{ Um mês em AC } & \multicolumn{2}{|c|}{ Oito meses em AC } \\
\hline & Incidência (\%) & Controle $(\%)$ & Incidência (\%) & Controle $(\%)$ \\
\hline & \multicolumn{4}{|c|}{ Frutos inoculados } \\
\hline Testemunha & $66,66 \mathrm{a}^{(1)}$ & - & $51,42 \mathrm{a}^{(2)}$ & - \\
\hline $50^{\circ} \mathrm{C}-12 \mathrm{~s}$ & $12,49 b$ & 81,26 & $17,14 b$ & 66,66 \\
\hline UV-C ${ }^{(1)}$ & $12,49 b$ & 81,26 & $22,85 b$ & 55,56 \\
\hline $50^{\circ} \mathrm{C}-12 \mathrm{~s}+\mathrm{UV}-\mathrm{C}^{(5)}$ & $0,00 \mathrm{c}$ & 100,00 & $17,14 \mathrm{~b}$ & 66,66 \\
\hline \multirow[t]{2}{*}{$\mathrm{CV}(\%)$} & 27,64 & - & 28,35 & - \\
\hline & \multicolumn{4}{|c|}{ Frutos com infecção natural } \\
\hline Testemunha & $15,55 \mathrm{a}^{(3)}$ & - & $11,66 \mathrm{a}^{(4)}$ & - \\
\hline $50^{\circ} \mathrm{C}-12 \mathrm{~s}$ & $7,21 \mathrm{~b}$ & 53,63 & $3,33 b$ & 71,44 \\
\hline$U V-C^{(5)}$ & $5,55 b$ & 64,30 & $3,33 b$ & 71,44 \\
\hline $50^{\circ} \mathrm{C}-12 \mathrm{~s}+\mathrm{UV}-\mathrm{C}^{(5)}$ & $5,55 \mathrm{~b}$ & 64,30 & $2,49 b$ & 78,64 \\
\hline $\mathrm{CV}(\%)$ & 24,97 & - & 27,84 & - \\
\hline
\end{tabular}

${ }^{(1)}$ Médias de quatro repetições de três frutos. ${ }^{(2)}$ Médias de sete repetições de cinco frutos. ${ }^{(3)}$ Médias de seis repetições de 30 frutos.

(4) Médias de quatro repetições de 30 frutos. ${ }^{(5)}$ Dose de radiação UV-C $=0,0069 \mathrm{~kJ} \mathrm{~m}^{-2}$.

Dados seguidos da mesma letra, na coluna, não diferem entre si, pelo teste de Tukey $(\mathrm{p}<0,05)$.

TABELA 2 - Estimativa do número de unidades formadoras de colônias (UFC) por fruto e nível de controle (\% em relação à testemunha); incidência (\%) e controle (\% em relação à testemunha) da podridão olho-de-boi (POB) em maçãs 'Gala' armazenadas por cinco meses em $\mathrm{AC}\left(2,0 \mathrm{kPa}\right.$ de $\mathrm{O}_{2}+1,5$ $\mathrm{kPa}$ de $\mathrm{CO}_{2}$ ), a $0,5^{\circ} \mathrm{C}$ e $95 \% \mathrm{UR}$, inoculadas com Crysptosporiopsis perennans e submetidas a tratamentos com aspersão hidrotérmica e radiação UV-C, em uma linha comercial de seleção.

\begin{tabular}{lcccc}
\hline \multirow{2}{*}{ Tratamento } & \multicolumn{2}{c}{ UFC } & \multicolumn{2}{c}{ POB } \\
\cline { 2 - 5 } & UFC fruto $^{-1(1)}$ & Controle (\%) & Incidência (\%) & Controle (\%) \\
\hline Testemunha & $12.775,00 \mathrm{a}^{(2)}$ & - & $59,51 \mathrm{a}$ & $(3)$ \\
$50^{\circ} \mathrm{C}-12 \mathrm{~s}$ & $1.632,00 \mathrm{~b}$ & 87,22 & $17,50 \mathrm{~b}$ & - \\
$\mathrm{UV}-\mathrm{C}^{(4)}$ & $0,00 \mathrm{c}$ & 100,00 & $18,37 \mathrm{~b}$ & 69,13 \\
\hline $\mathrm{CV}(\%)$ & 34,79 & - & 14,67 & - \\
\hline
\end{tabular}

${ }^{(1)} \mathrm{UFC}$ fruto ${ }^{-1}=\left(\left(\left(\mathrm{N}^{\mathrm{o}}\right.\right.\right.$ de UFC/placa $\left.) * 2000\right) / \mathrm{N}^{\mathrm{o}}$ de frutos $) .{ }^{(2)}$ Médias de quatro repetições de três placas. ${ }^{(3)}$ Médias de oito repetições de 10 frutos. ${ }^{(4)}$ Dose de radiação UV-C $=0,0069 \mathrm{~kJ} \mathrm{~m}^{-2}$.

Dados seguidos da mesma letra, na coluna, não diferem entre si, pelo teste de Tukey $(\mathrm{p}<0,05 \%)$. 
TABELA 3 - Incidência (\%) e controle (\% em relação à testemunha) da podridão olho-de-boi (POB) em maçãs 'Gala', após cinco meses de armazenamento em $\mathrm{AC}\left(2,0 \mathrm{kPa}\right.$ de $\mathrm{O}_{2}+1,5 \mathrm{kPa}$ de $\left.\mathrm{CO}_{2}\right)$, a $0,5^{\circ} \mathrm{C}$ e $95 \%$ UR, com infecção natural, submetidas a tratamentos físicos, em uma linha comercial de seleção.

\begin{tabular}{lcc}
\hline \multirow{2}{*}{ Tratamento } & \multicolumn{2}{c}{ POB } \\
\cline { 2 - 3 } & Incidência (\%) & Controle (\%) \\
\hline Testemunha & $2,09 \mathrm{a}^{(1)}$ & - \\
$50^{\circ} \mathrm{C}-12 \mathrm{~s}$ & $0,31 \mathrm{~b}$ & 85,16 \\
$\mathrm{UV}-\mathrm{C}{ }^{(2)}$ & $0,16 \mathrm{~b}$ & 92,34 \\
\hline $\mathrm{CV}(\%)$ & 12,58 & - \\
\hline
\end{tabular}

${ }^{(1)}$ Médias de quatro repetições de 100 frutos. ${ }^{(2)}$ Dose de radiação UV-C $=0,0069 \mathrm{~kJ} \mathrm{~m}^{-2}$. Dados seguidos da mesma letra na coluna não diferem entre si, pelo teste de Tukey $(\mathrm{p}<0,05 \%)$.

TABELA 4 - Análise econômica do uso da aspersão hidrotérmica e da radiação UV-C em pós-colheita, para o controle da podridão olho-de-boi em maçãs 'Fuji' e 'Gala', tratadas após armazenamento em AC.

\begin{tabular}{|c|c|c|c|c|}
\hline \multirow{2}{*}{ Tratamento } & \multicolumn{2}{|c|}{ Benefício $\left(\mathrm{R} \$ \mathrm{dia}^{-1}\right)^{\mathrm{X}}$} & \multicolumn{2}{|c|}{ Retorno $\left(\mathrm{R} \$_{\text {retorno }} / \mathrm{R} \$_{\text {investido }}\right)^{\mathrm{Y}}$} \\
\hline & 'Fuji' (1) & 'Gala'(2) & 'Fuji'(1) & 'Gala'(2) \\
\hline $50^{\circ} \mathrm{C}-12 \mathrm{~s}$ & $4.700,00$ & 337,00 & 7,70 & 1,48 \\
\hline $\mathrm{UV}-\mathrm{C}^{(3)}$ & $5.845,00$ & 954,00 & 64,00 & 11,32 \\
\hline $50^{\circ} \mathrm{C}-12 \mathrm{~s}+\mathrm{UV}-\mathrm{C}^{(3)}$ & $5.416,00$ & - & 7,80 & - \\
\hline
\end{tabular}

\footnotetext{
XValor determinado pela diferença nas perdas entre a testemunha e as perdas nos tratamentos físicos, levando em consideração o custo destes. ${ }^{Y}$ Valor determinado pelo quociente entre o valor investido (custo do sistema + custo de aplicação) e o benefício.

(1) Média de maçãs armazenadas durante um e oito meses sob AC.

(2) Em maçãs armazenadas por cinco meses sob AC.

${ }^{(3)}$ Dose de radiação UV-C $=0,0069 \mathrm{~kJ} \mathrm{~m}^{-2}$.
}

\section{CONCLUSÕES}

1- Em maçãs 'Fuji' armazenadas em condição de AC por um e oito meses, inoculadas ou com infecção natural, o uso da aspersão hidrotérmica a $50^{\circ} \mathrm{C}$, durante 12 segundos, e/ou radiação UV-C na dose de $0,0069 \mathrm{~kJ} \mathrm{~m}^{-2}$ reduz a incidência da podridão olho-de-boi.

2- Em maçãs 'Gala', com cinco meses de armazenamento em $\mathrm{AC}$, a aspersão hidrotérmica a $50^{\circ} \mathrm{C}$, durante 12 segundos, ou a radiação UV-C na dose de $0,0069 \mathrm{~kJ} \mathrm{~m}^{-2}$ reduz o número de unidades formadoras de colônias e a incidência de podridão em frutos inoculados com C. perennans, e reduz a incidência da podridão olho-de-boi em frutos com infecção natural.

3- O uso da radiação UV-C, em ambas as cultivares, é o tratamento que apresenta maior benefício e retorno econômico.

\section{AGRADECIMENTOS}

À CAPES, ao CNPq e ao Projeto Inova Maçã, pelo apoio financeiro; às Empresas Rasip Agro Pastoril e à Proterra Engenharia Agronômica, pela infraestrutura e recursos disponibilizados; e aos Pesquisadores Mara R. Rizzatti e João Antônio V. de Souza, do Departamento de Física das Radiações da PUC/RS, pelo suporte técnico na calibração do radiômetro.

\section{REFERÊNCIAS}

AGROLINK. Cotações. Disponível em: < http:// www.agrolink.com.br/>. Acesso em: 20 jan. 2011.

BARTNICKI, V.A.; VALDEBENITO-SANHUEZA, R.M.; AMARANTE, C.V.T.; CASTRO, L.A.S.; RIZZATTI, M.R.; SOUZA, J.A.V. Água aquecida e radiação UV-C no controle pós-colheita de Cryptosporiopsis perennans em maçãs. Pesquisa Agropecuária Brasileira, Brasília, v.45, n.2, p.124-131, 2010.

BRASIL. Ministério da Agricultura, Pecuária e Abastecimento. Instrução Normativa 50. Regulamento técnico de identidade e de qualidade para a classificação de maçã. Brasília, 2002. 11p. 
BORSANI, J.; BUDDE, C.O.; PORRINI, L.; LAUXMANN, M.A.; LOMBARDO, V.A.; MURRAY, R.; ANDREO, C.S.; DRINCOVICH, M.F.; LARA, M.V. Carbon metabolism of peach fruit after harvest: changes in enzymes involved in organic acid and sugar level modifications. Journal of Experimental Botany, Lancaster, v.60, n.6, p.1823-1837, 2009.

CHUN, H.H.; KIM, J.Y.; SONG, K.B. Inactivation of foodborne pathogens in ready-to-eat salad using UV-C irradiation. Food Science and Biotechnology, Seul, v.19, n.2, p.547-551, 2010.

DEMIRCI, A.; PANICO, L. Pulsed ultraviolet light. Food Science and Technology International, London, v.14, n.5, p.443-446, 2008.

EDNEY, K.L.; BURCHILL, R.T. The use of heat to control the rotting of Cox's Orange Pippin apples by Gloeosporium spp. Annals of Applied Biology, Kent, v.59, n.3, p.389-400, 1967.

FALLIK, E. Prestorage hot water treatments (immersion, rinsing and brushing). Postharvest Biology and Technology, Amsterdam, v.32, n.1, p.125-134, 2004.

JIN, P.; ZHENG, Y.; TANG, S.; RUI, H.; WANG, C.Y. A combination of hot air and methyl jasmonate vapor treatment alleviates chilling injury of peach fruit. Postharvest Biology and Technology, Amsterdam, v.52, n.1, p.24-29, 2009.

LI, X.; ZHENG, X.; YAN, S.; LI, S. Effects of salicylic acid (SA), ultraviolet radiation (UV-B and UV-C) on trans-resveratrol inducement in the skin of harvested grape berries. Frontiers of Agriculture in China, Pequim, v.2, n.1, p.77-81, 2008.

LU, J.Y.; LUKOMBO, S.M.; STEVENS, C.; KHAN, V.A.; WILSON, C.L.; PUSEY, P.L.; CHAULTZ, E. Low dose UV and gamma radiation on storage rot and physicochemical changes in peaches. Journal of Food Quality, Westport, v.16, n.4, p.301-309, 1993.

LURIE, S. The effect of high temperature treatment on quality of fruits and vegetables. Acta Horticulturae, Leuven, n.712, p.165-173, 2006.

MAXIN, P.; KLOPP, K.; HUYSKENS-KEIL, S.; EBERT, G. Control of postharvest decay in organic grown apples by hot water treatment. Acta Horticulturae, Leuven, n.682, p.2153-2158, 2005.
RGE - Rio Grande Energia. Tarifas. Disponível em: <http://www.rge-rs.com.br $>$. Acesso em: 1 nov. 2010

SADIQ, R.; RODRIGUEZ, M.J. Disinfection byproducts (DBPs) in drinking water and predictive models for their occurrence: a review. Science of the Total Environment, Québec, v.321, n.1-3, p.21-46, 2004

SAMS, C.E.; CONWAY, W.S.; ABBOTT, J.A.; LEWIS, R.J.; BEN-SHALOM, N. Firmness and decay of apples following postharvest pressure infiltration of calcium and heat treatment. Journal American Society Horticultural Science, Alexandria, v.118, n.5, p. 623-627, 1993.

SAS INSTITUTE. Getting started with the SAS learning edition. Cary, 2002. 200p.

SAUTTER, C.K.; STORCK, L.; RIZZATTI, M.R.; MALLMANN, C.A.; BRACKMANN, A. Síntese de transresveratrol e controle de podridão em maçãs com uso de elicitores em pós-colheita. Pesquisa Agropecuária Brasileira, Brasília, v.43, n.9, p.10971103, 2008.

SOMMERS, C.H.; SITES, J.E.; MUSGROVE, M. Ultraviolet light (254 nm) inactivation of pathogens on foods and stainless steel surfaces. Journal of Food Safety, Hoboken, v.30, n.2, p.470-479, 2010.

SPOLTI, P.; VALDEBENITO-SANHUEZA, R.M.; DEL PONTE, E.M. Meio semisseletivo para recuperação e quantificação de Cryptosporiopsis perennans em maçãs. Ciência Rural, Santa Maria, v.40, n.3, p.661-665, 2010.

STEVENS, C.; KHAN, V.A.; WILSON, C.L. The effect of fruit orientation of postharvest commodities following low dose ultraviolet light-C treatment on host induced resistance to decay. Crop Protection, Ames, v.24, n.8, p.756-759, 2005.

STEVENS, C.; WILSON, C.L.; LU, J.Y.; KHAN, V.A.; CHALUTZ, E.; DROBY, S.; KABWE, M.K.; HAUNG, Z.; ADEYEYE, O.; PUSEY, L.P.; WISNIEWSKY, M.E.; WEST, M. Plant hormesis induced by ultraviolet light $\mathrm{C}$ for controlling postharvest diseases of tree fruits. Crop Protection, Ames, v.15, n.2, p.129-134, 1996. 
VALDEBENITO-SANHUEZA, R.M. Ocorrência de Cryptosporiopsis perennans em macieiras 'Fuji' no Sul do Brasil. Summa Phytopathologica, Botucatu, v.28, n.2, p.204-206, 2002.

VALDEBENITO-SANHUEZA, R.M.; MAIA, L. Utilização da luz ultravioleta (UV-C) na proteção de maçãs 'Fuji' da podridão por Penicillium expansum. Bento Gonçalves: Embrapa Uva e Vinho, 2001. 20p. (Boletim de Pesquisa e Desenvolvimento, $10)$.
VALDEBENITO-SANHUEZA, R.M.; SPOLTI, P.; DEL PONTE, E.M. Controle do inóculo inicial para redução dos danos pela podridão-'olho-de-boi' em macieiras. Revista Brasileira de Fruticultura, Jaboticabal, v.32, n.4, p.1044-1054, 2010. 